\title{
Metastasis of Rare Tumor at an Usual Site-A Case Report
}

Avinash R Joshi, Rupali R Bavikar* and Tejal khande

Department of Pathology, Smt Kashibai Navale Medical College, Pune, India

*Corresponding author: Rupali R Bavikar, Department of Pathology, Smt Kashibai Navale Medical College, Pune, India 411001, Tel: +91 8149367249; Fax: +91 20 2612 68; E-mail: rupalibavikar@yahoo.co.uk

Rec date: Jul 26, 2014, Acc date: Sep 17, 2014, Pub date: Sep 19, 2014

Copyright: (C) Joshi AR, et al. This is an open-access article distributed under the terms of the Creative Commons Attribution License, which permits unrestricted use, distribution, and reproduction in any medium, provided the original author and source are credited.

\begin{abstract}
Metastasis to the breast from extra mammary sites is very rare, constituting only 1 to 2 percent of metastasis. Lymphoma, malignant melanoma and bronchial carcinoma are the malignancies which metastasize to the breast. Metastasis to the breast in a case of primary anorectal melanoma is rare with only few cases reported in literature.
\end{abstract}

We present a case of a 40 year old female who presented with a lump in the left breast. She had history of malignant melanoma of anorectal region for which she underwent anterior resection 6 months back. We did FNAC of left breast lump and found metastasis. Unfortunately patient died within few days.

\section{Introduction}

Primary anorectal melanoma is very rare. The incidence is $1-3 \%$ of all anorectal malignancies. Most of these cases occur between the fifth to sixth decade of life [1]. The tumor has very high metastasic potential. Metastasis of anorectal melanoma to breast is very rare. Only few cases are reported in literature [2,3]. The rarity of this case has prompted us to present this case.

\section{Case History}

A 50 year old female presented with lump in left breast since 6 months. She had a previous history of malignant melanoma of anorectal region with positive lymph nodes in pelvic and left inguinal region. The patient was operated and was on chemotherapy. We received a specimen of rectum measuring $20 \times 6 \times 2 \mathrm{~cm}$. It was showing an ulceroproliferative growth with blackish discoloration and measuring $5 \times 4 \times 2.8 \mathrm{~cm}$. The rectal mass on histopathology examination was a malignant melanoma. The tumor was invading the muscularis propria. On Immunochemistry, the tumor was positive for s100 and Malan A and negative for HMB 45, CK and LCA. She was asymptomatic for 6 months post operatively when she noticed a painless, small lump in the left breast. The lump gradually increased in size. On examination, a lump was present in upper and inner quadrant of left breast measuring around $6 \times 5 \times 4 \mathrm{~cm}$ (Figure 1). The lump was not fixed to the underlying structures. The external surface of lump was bosselated and consistency was varying from soft, firm to hard. FNAC done from different areas yield same picture. The smears showed round to polygonal cells arranged in groups and singly scattered (Figure 2). Binucleated and multinucleated cells were also seen (Figure 3). The nuclei were hypercromatic, pleomorphic with prominent 1-2 nucleoli. Black colored pigment was seen in cytoplasm of malignant cells and also in macrophages (Figure 4). Special stain Masson's Fontana confirmed the presence of melanin [Figure 5].

\section{Discussion}

Anorectal melanoma is a very rare tumor with incidence of $1-3 \%$ of all anorectal tumors. They are common in fifth to sixth decade of life.
They have high malignant potential. It is reported that $38 \%$ of tumor metastasize at the time of diagnosis [4]. They spread by haematogenous or lymphatic route. Distant metastasis is common to lungs, liver and bone. Metastasis to breast is rare and very few cases are reported in literature.

Metastasis to breast from extramammary tumors is uncommon accounting to 1.3 to $6.6 \%$ of all malignant tumors of the breast [5]. The extra mammary tumors often mestasising to breast include lymphoma, cutaneous melanoma and lung tumors [6]. The most common primary sites of melanoma that metastasize to the breast are the upper trunk and upper extremities; lower extremity primary lesions rarely metastasize to the breast [7]. Because proximity seems to matter, it has been postulated that spread to the breast may occur through lymphatic channels, as well as hematogenously [2]. Metastasis from anorectal melanoma to breast is very very rare .Only few cases are described in literature.

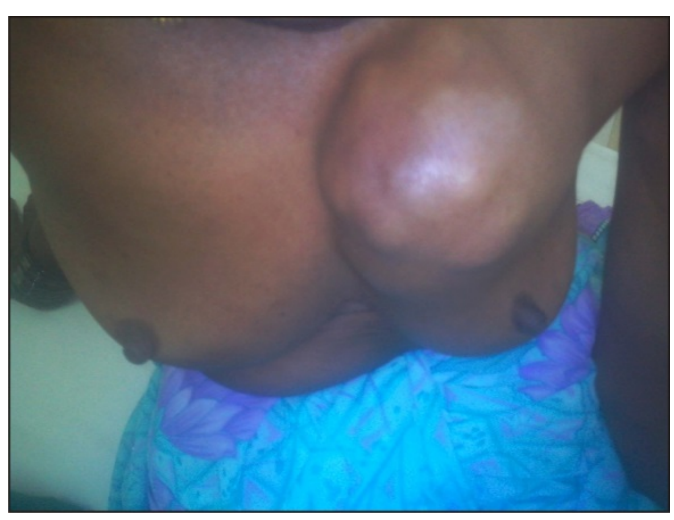

Figure 1: shows patient presented with lump in left breast measuring around $6 \times 5 \times 4 \mathrm{~cm}$ in upper and inner quadrant. 


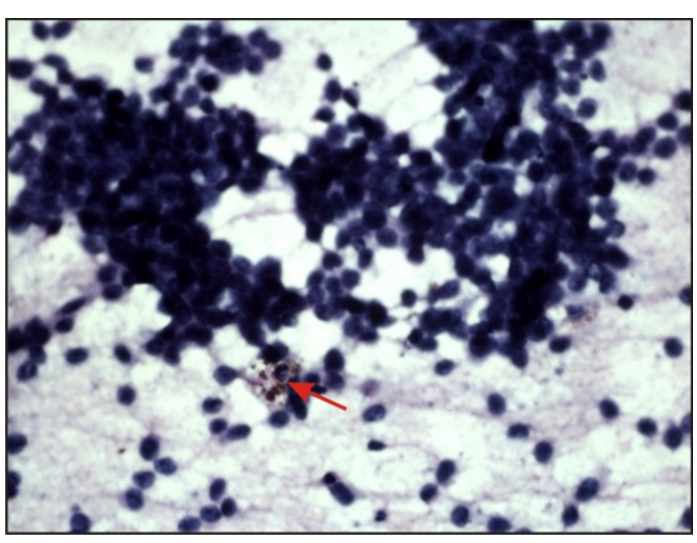

Figure 2: [H\&E 100X] smear shows malignant cells arranged in group and clusters and singly scattered. The cells have hyperchromatic pleomorphic nuclei and scanty cytoplasm. The arrow shows malignant cell containing melanin pigment.

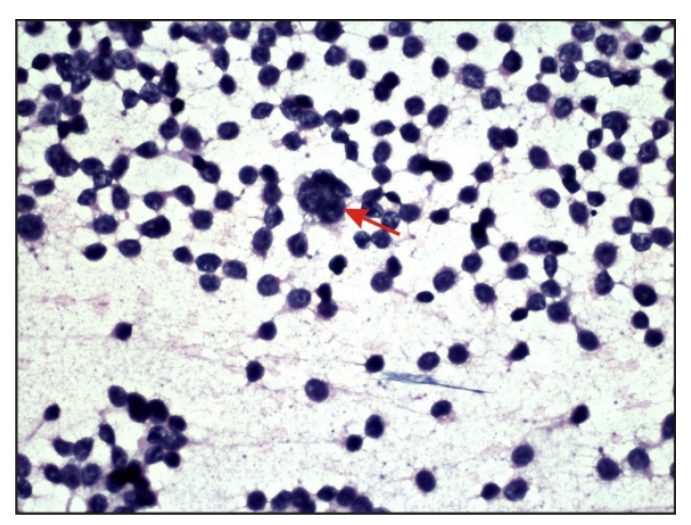

Figure 3: [H\&E $400 \mathrm{X}]$ shows multinucleated giant cell.

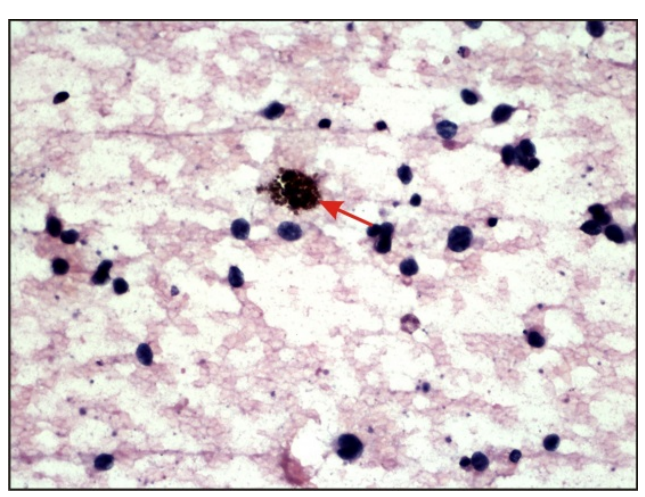

Figure 4: [H\&E 400X] shows macrophage containing melanin pigment.

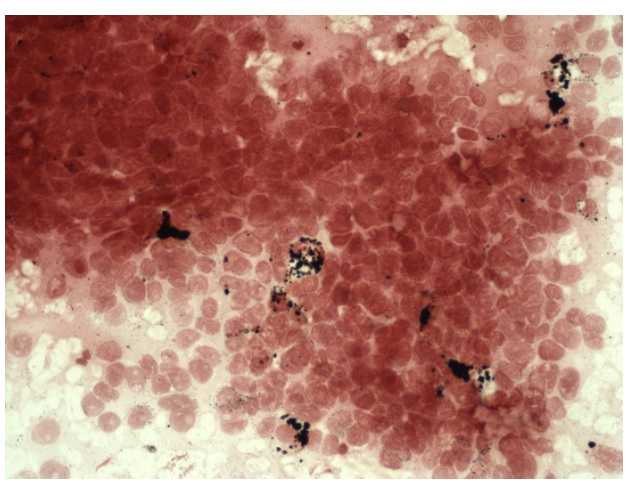

Figure 5: shows Masson Fontana to demonstrate melanin pigment.

Primary and metastatic disease of breast is difficult to differentiate on the basis of clinical and radiological findings. The differentiation is necessary because of the different treatment which needs to be given to the patient. Wide local exicion is sufficient to control metastatic disease of breast. It is essential to recognize malignant tumors in the breast as metastatic malignant melanoma to avoid unnecessary surgery.

The treatment of metastatic malignant melanoma to breast melanoma to breast is excision of the lesion with clear margins, followed by systemic therapy for disease. Regardless of surgical treatment, widespread disseminated disease has poor prognosis with five year survival of less than $20 \%$ [8].

It is postulated that metastasis from anal malignant melanoma occurs in younger females and it has hormonal influence [9]. The relatively young age at diagnosis has been attributed to the fact that the breast is not a favorable site for metastasis after menopause because of the larger areas of fibrous tissue and the relatively poor blood supply [10]. Others have suggested a direct role of estrogen in facilitating metastatic spread [9]. Metastasis to breast is usually associated with wide spread dissemination of the tumor to brain, lung and liver. Though our patient did not show any such signs and symptoms, complete evaluation of patient should be done. In our case, this could not be done as patient expired within few days. Lung metastasis was suspected cause of death.

To conclude, primary anorectal melanoma with metastasis to the breast is rare with only few cases reported. It is essential to diagnose this correctly as the prognosis and treatment depends on the diagnosis.

\section{References}

1. Klas JV, Rothenberger DA, Wong WD, Madoff RD (1999) Malignant tumors of the anal canal: the spectrum of disease, treatment, and outcomes. Cancer 85: 1686-1693.

2. Lee JF, Leung KL, Leow CK, Lau WY (1999) An unusual case of breast metastasis from an anorectal melanoma. Eur J Surg Oncol 25: 441-442.

3. Ozgüroglu M, Ozaras R, Tahan V, Demirkesen C, Demir G, et al. (1999) Anorectal melanoma metastatic to the breast. J Clin Gastroenterol 29: 197-199.

4. Podnos YD, Tsai NC, Smith D, Ellenhorn JD (2006) Factors affecting survival in patients with anal melanoma. Am Surg 72: 917-920.

5. Bassi F, Gatti G, Mauri E, Ballardini B, De Pas T, et al. (2004) Breast metastases from cutaneous malignant melanoma. Breast 13: 533-535. 
Citation: Joshi AR, Bavikar RR, Khande T (2014) Metastasis of Rare Tumor at an Usual Site-A Case Report. J Cytol Histol 5: 280. doi: 10.4172/2157-7099.1000280

Page 3 of 3

6. Oksuzoglu B, Abali H, GÃler N, Baltali E, OziÅŸik Y (2003) Metastasis to the breast from nonmammarian solid neoplasms: a report of five cases. Med Oncol 20: 295-300.

7. Hajdu SI, Urban JA (1972) Cancers metastatic to the breast. Cancer 29: 1691-1696.

8. Belli F, Gallino GF, Lo Vullo S, Mariani L, Poiasina E, et al. (2009) Melanoma of the anorectal region: the experience of the National Cancer Institute of Milano. Eur J Surg Oncol 35: 757-762.
9. Arora R, Robinson WA (1992) Breast metastases from malignant melanoma. J Surg Oncol 50: 27-29.

10. Kim SM, Park JM (2003) Computed tomography of the breast. Abnormal findings with mammographic and sonographic correlation. J Comput Assist Tomogr 27: 761-770. 